\title{
Miraculous Healing of Metastatic Squamous Cell Carcinoma - The Role of Adjunctive Energy Healing
}

\author{
Richard L Sarnat* \\ Chief Medical Officer, Advanced Medicine Integration Group LLC, USA
}

Submission: December 06, 2018; Published: January 09, 2019

*Corresponding author: Richard L Sarnat, Chief Medical Officer, Advanced Medicine Integration Group LLC, 473 Central Ave. Highland Park, Illinois 60035, USA

Abstract

While "miraculous healings" or spontaneous remissions of various disease states have been scientifically reported previously, the exact mechanism, which allow for these seeming miracles or spontaneous remissions is poorly understood. By contrast, I have recently published multiple case studies, which have included the "miraculous healings" of Sarcoidosis, Chronic Lyme Disease, Fibromyalgia, Parkinson's disease and severe chronic debilitating plantar arthritis without the use of pharmaceuticals or antibiotics and where the mechanism of action used to initiate the "miraculous healing" appears to have a cause and effect relationship and thus is reproducible.

This case report now adds Metastatic Squamous Cell Carcinoma (case study \#6) to the previous five case studies, which I have observed and now report to be successfully treated by a process, which Master John Douglas refers to as "Angelic Reformation." These case reports are representative of the many hundreds of case studies I have documented (although most yet unpublished) over a ten-year period, while observing the work of Master John Douglas and the graduates of his Elite Development course. While certainly inspiring, admittedly all of these observations must ultimately be subjected to additional rigorous scientific methodology. Yet, the sheer number of miraculous healings I have observed and the fact that this body of knowledge can be taught to others who obtain similarly effective results is very promising, given our current confusion regarding the exact mechanisms of action and/or causation of autoimmune diseases, Parkinson's disease, chronic debilitating arthropathies and most of all cancers, which were estimated to have a global cost burden of $\$ 1.16$ trillion dollars per year as of 2010 statistics.

Keywords: Metastatic Squamous Cell Carcinoma; Miraculous healing; Spontaneous remission; Angelic Reformation

\section{Case Presentation}

Case study \#6 is a 65-year-old white female who first discovered she had biopsy proven T1/T2 N0 invasive squamous cell carcinoma of the anus in June of 2008. After a course of 5FU, Mitomycin-C and 5,400cGy of radiation, follow up re-staging scans in November of 2008 showed no evidence of recurrence or metastatic disease.

Unfortunately, by January of 2010, re-staging scans found a discrete focus of intense abnormal activity with an SUV biomarker up-take level of 10.7 identified in the left para-aortic node and two small sites of uptake in the aortic valve, all consistent with metastasis. Biopsy of a $1.3 \mathrm{~cm}$ node showed metastatic squamous cell carcinoma with additional affected nodes that were not regional or clustered together, which as a clinical sign gave a presumptive diagnosis of systemic metastatic disease.

The impression that her oncologist wrote post biopsy in the patient's history and physical was, that "treatment would be palliative, that the chance of cure is small to none."

Although the patient started five doses of FOLFOX, she did not avail herself of the recommended follow-up radiation therapy and instead self discharged; in her own words, "to look for a miracle."
This patient first encountered Master John Douglas, an energy healer, on July 8th, 2010.

She describes the experience of being with Master John as, "feeling very light as I was sitting within the energy aura of Master John Douglas, which felt like sitting in a candle lite circle filled with peace, innocence, protection, love and a state of simplicity where all worries were gone." She also experienced what she believed was, "the presence of Angelic Beings in the room cradling her and sprinkling sparks of stardust inside her. Suddenly she felt a 'snap' in her lower belly and chest and watched and allowed an oily vapor to come out of her and dissipate into the air. "

On the other side of the equation, Master John Douglas reports that, "I remember that this patient was a faithful, kind and gentle person, who showed no cynicism or doubts about her potential to be healed. The moment that we met together during the five-minute personalized healing session, I could directly and clairvoyantly view the cancerous cells and proceeded to apply the Angelic reformation to her physiology on a molecular level. Due to her spiritual worthiness, what ensued was remarkable - the cells that were cancerous literally reformed before my eyes and 
all energetic structures of the cancerous cells were expelled and instantly replaced by healthy structures.

As always, being cautious, I wished her well, and told her that she had received a very special healing that few have received previously. She appeared to be in awe, so I knew she experienced something profound."

A few months after the healing session described above, restaging scans ordered by a new oncologist showed no evidence of her former metastatic disease. Subsequent PET scans which were multi-station, co-registered PET/CT (non-contrast, low dose) images of the mid skull to upper thighs obtained on a Siemens Sensation 16 Biograph PET=CT Fusion Scanner and CT scans of the neck/chest/abdomen/pelvis with and without contrast performed in October of 2011 continued to show no evidence of active neoplastic intra-abdominal disease.

This patient remained in remission without any further conventional medical treatments until January of 2013, when a reoccurrence of her original disease was found to be present in the retroperitoneal space. Since that reoccurrence, she has used a combination of conventional oncological approaches along with continued utilization of many of the processes of angelic reformation as taught by Master John Douglas.

Patient to this day continues to be very grateful to Master John Douglas for delivering her miracle cure. She has become an Elite Development graduate and is still working full time in her chosen profession and active in all aspects of life.

\section{Discussion}

As I have recently reported elsewhere [1-3], Master John Douglas uses his clairvoyant senses to identify the infectious etiology and root cause of many "idiopathic" diseases. Although the infectious agents for these idiopathic diseases have not been discovered or reported in the scientific literature, he claims to be able to directly visualize the existence of hundreds of unknown infectious agents through his enhanced (clairvoyant) senses, no different than we observe ordinary phenomena in the material world, such as the leaves on trees.

The credibility of this assertion is supported by the fact that annually, open to the public, he teaches hundreds of students to replicate his findings at a seminar called the Elite Development Course. To date, over 500 people have been trained to detect these hidden infectious agents by a method called "scanning", which enables the observer, phenomenologically, on the level of consciousness, to measure the unique electromagnetic wave signal emanating from each unique infectious agent, analogous to the way each unique element of the periodic table has a corresponding unique molecular weight.

Granted, most of theseinfectious agents haveyet to beidentified by virologists, microbiologists, parasitologists or any conventional medical apparatus. And while the inability to verify the existence of these infectious agents apart from consensus among Elite Course graduates is disruptive to our conventional medical paradigm, is this claim all that different from saying that prior to an electron microscope, many minute infectious agents were not seen with an ordinary light microscope or that the essential elements of quantum physics which were mathematically deduced could not be proven without the technological advancement which allowed for the building a linear particle accelerator? While admittedly this technology is consciousness-based and does not exist as an external device currently, philosophically I believe that there is no barrier to replicating these findings using an external device as technology advances.

Historically there was a time in the not too distant past where the idea of an infectious agent as the root cause of cancer would have been heretical. Yet now we know that in the developing world nearly $20 \%$ of all cancers are really secondary manifestations of disease due to earlier antecedent infections, such as hepatitis B, hepatitis $\mathrm{C}$ and human papillomavirus infection [4].

From the standpoint of an energy healer, cancer is really an immune system disease, where the normal protective mechanisms to identify "self" from "non-self" break down. Using the method of "scanning," as taught at the Elite Development Course, all cancer patients with active disease register an electromagnetic bio-energetic signal of near "zero activity" when measuring their immune systems ability to recognize the presence of the multiple infectious agents responsible for the formation of malignant cells or recognizing the malignant cell receptors at all.

So, from an energetic standpoint, one aspect of curing cancer is to reawaken the inherent ability of the immune system to function normally and enable it to both recognize and attack the infectious agents within the malignant cells. The healer by intention can energize killer cells to both recognize the previously cloaked cancer receptors and destroy them. Modern immunotherapies are targeted to accomplish this same goal by different mechanisms.

\section{Study Limitations}

Admittedly, this case report has many limitations. While the original diagnosis was established by an oncologist and corroborated by radiographic studies and tissue biopsy, the patient did have a two-year remission after her original treatments in 2008 attributable to conventional therapy alone. Thus, the possibility exists that this subsequent remission is merely a delayed response to her incomplete FOLFOX treatment, even though this is unlikely.

Even the role of the placebo effect must be considered as a variable triggering the self-reported transformation, which was subjectively experienced in the presence of Master John Douglas.

I also realize that as "scanning" is a consciousness-based technique, not common to the public at large, and only mastered by graduates of the Elite Development Course as taught by Master John Douglas, this limits the population of "experts" capable of confirming or refuting the accuracy of this report to under 500 current graduates. So it is entirely reasonable to question a "miraculous cure" that rests entirely on the resolution of symptoms as reported by the patient, except for the fact that 500 people are independently capable of measuring the presence of 
the frequency of an infectious agent and/or cancer cell signals which is killed by conscious intention and then observe that the resolution of symptoms is closely correlated in time with the disappearance of that infectious agent's electromagnetic signal (as measured by the process of "scanning").

\section{Conclusion}

Notwithstanding the obvious limitations of the study as listed above, I still believe that the sheer number of seeming "miraculous healings" which I have witnessed over a ten year period and the fact that this ability can be taught and reproduced by many licensed health professionals forces us to consider the possibility that a cause and effect relationship exists as the underlying mechanism of the "miraculous healings" which have been reported. Furthermore, given the risk of adverse events surrounding the conventional pharmaceutical, radiological and surgical treatment of cancers, the downside of using energy healing seems innocuous by comparison to the known risks of these well documented adverse events.

And while it is cautionary to note the reoccurrence of the original disease, even after a "miraculous cure" that afforded the patient three years of an improbable remission, this increased risk of reoccurrence in all treated cancer patients appears to be a fact we must accept, whether the treatment is conventional oncology or energy healing by angelic reformation.

Nonetheless, it seems prudent for all non-pharmaceutical and non-surgical options such as the technology described herein to be further investigated, whenever the credible probability of their improved therapeutic benefit is known. Our goal as physicians is always to use the treatment option with the best therapeutic ratio, and thus minimize any iatrogenic component to our delivery of care. And while I realize that we are a long way off from having a solid scientific foundation to recommend the technology described herein, not to further investigate the reality of these observations in a more rigorous setting would be a mistake in my opinion [5]. If this report is further validated over time, how many more malignant conditions will we find that have an unknown infectious etiology as their root cause; and how many more remissions, even if temporary, will be documented that can provide high quality of life and extended the lifespans without the use of conventional oncological options, which can be expensive, heroic and have a high percentage of adverse side effects and morbidity?

\section{Acknowledgment}

I would like to acknowledge Master John Douglas for his tireless work ethic and his passion to save humanity from the unseen dangers, which threaten life on this planet and to the real people in our anonymous case studies who were willing to share their intimate medical experiences for the benefit of science.

\section{Conflict of Interest}

The author declares that no competing interests exist and that he has no financial gain from his relationship with Master John Douglas or the Elite Development course. While some peer reviewers may feel that a possible financial bias exists from even naming Master John Douglas or the existence of the Elite Development Course, in the interests of scientific transparency I do not see how this is any different from naming a proprietary pharmaceutical and dosage which is thought to have a positive effect for the amelioration of a given disease state. In both cases, proprietary issues notwithstanding, the roadmap, which was undertaken by the patient to achieve improvement must be transparent to the reader.

\section{References}

1. Sarnat R (2018) Miraculous Healings of Chronic Lyme disease, Fibromyalgia and Sarcoidosis without the Use of Pharmaceuticals or Antibiotics. OBM Integrative and Complementary Medicine 3(1): 3.

2. Sarnat RL (2018) Miraculous Healing of Parkinson's disease Without the Use of Pharmaceuticals, Antibiotics or Surgery. Advances in Complementary \& Alternative Medicine 3(2).

3. Sarnat RL (2018) Miraculous healing of Severe Chronic Debilitating Plantar Arthropathy Without the use of Surgery or Pharmaceuticals. ACTA Scientific Orthopaedics 1(3): 23-27.

4. Plummer M, de Martel C, Vignat J, Ferlay J, Bray F, et al. (2016) Global burden of cancers attributable to infections in 2012: a synthetic analysis. Lancet Glob Health 4(9): e609-16.

5. Jonas WB, Crawford1 C, Colloca L, Kaptchuk TJ, Moseley B, et al. (2015) To what extent are surgery and invasive procedures effective beyond placebo response? A systematic review with meta-analysis of randomized, sham controlled trials. BMJ Open 5(2015): e009655.

\section{Your next submission with Juniper Publishers will reach you the below assets}

- Quality Editorial service

- Swift Peer Review

- Reprints availability

- E-prints Service

- Manuscript Podcast for convenient understanding

- Global attainment for your research

- Manuscript accessibility in different formats

( Pdf, E-pub, Full Text, Audio)

- Unceasing customer service

Track the below URL for one-step submission

https://juniperpublishers.com/online-submission.php 